E. M. Vinogradova, A. V. Starikova, M. I. Varayun'

\title{
MULTIPOLE ELECTROSTATIC SYSTEM MATHEMATICAL MODELING
}

St. Peterburg State University, 7-9, Universitetskaya nab., St. Petersburg, 199034, Russian Federation

This paper presents an electrostatic multipole system's mathematical modeling. The multipole system consists of an even number of equiform electrodes of an infinite length. The shape of each electrode can be arbitrary. The constant potential is equal in absolute value and sign-changing at neighboring electrodes. To calculate the potential distribution, each real electrode is changed by a virtual electrode whose surface coincides with an equipotential surface. The variable separation method is used to solve the boundary-value problem in plane polar coordinates. The electrostatic potential distribution is calculated in an analytic form over the entire region of the system. Refs 11 . Figs 5 .

Keywords: multipole system, electron-optical system, potential distribution, electrostatic potential, Laplace equation, Poisson equation.

\section{Е. М. Виноградова, А. В. Старикова, М. И. Вараюнъ}

\section{МАТЕМАТИЧЕСКОЕ МОДЕЛИРОВАНИЕ МУЛЬТИПОЛЬНОЙ ЭЛЕКТРОСТАТИЧЕСКОЙ СИСТЕМЫ}

Санкт-Петербургский государственный университет, Российская Федерация, 199034, Санкт-Петербург, Университетская наб., 7-9

В данной статье представлено математическое моделирование двумерной электростатической мультипольной системы. Мультипольную систему образует четное число электродов бесконечной длины с одним и тем же профилем. Форма профиля электрода может быть произвольной. На каждый из электродов подан потенциал, одинаковый по модулю для всех элементов системы и имеющий противоположный знак на соседних элементах. Для того чтобы найти распределение потенциала, каждый реальный электрод заменяется виртуальным, поверхность которого совпадает с определенной эквипотенциальной поверхностью. Для решения граничной задачи применяется метод разделения переменных в полярных координатах. Мультипольные электронно-оптические системы широко используются в электронно-вакуумных приборах, например, для коррекции сферической и хроматической аберрации низковольтного растрового электронного микроскопа, улучшения разрешения низковольтного сканирующего электронного микроскопа, для фокусировки и транспортировки пучков заряженных частиц. Распределение электростатического потенциала найдено в аналитической форме во всей области исследуемой системы, что позволяет решать задачи оптимизации при конструировании приборов электронной оптики. Библиогр. 11 назв. Ил. 5.

Ключевые слова: мультипольная система, электронно-оптическая система, распределение потенциала, электростатический потенциал, уравнение Лапласа, уравнение Пуассона.

Vinogradova Ekaterina Mikhailovna - doctor of physical and mathematical sciences, professor; e.m.vinogradova@spbu.ru

Starikova Anna Valerievna - postgraduate student; listrukova@rambler.ru

Varayun' Marina Ivanovna - PhD of physical and mathematical sciences, associate professor; m.varayuan@spbu.ru

Виноградова Екатерина Михайловна - доктор физико-математических наук, профессор; e.m.vinogradova@spbu.ru

Старикова Анна Валеръевна - аспирант; listrukova@rambler.ru

Вараюнъ Марина Ивановна - кандидат физико-математических наук, доцент; m.varayuan@spbu.ru

(C) Санкт-Петербургский государственный университет, 2017 
Introduction. Multipole electron-optical systems as the multipole correction-lens systems can be used for the third order spherical and chromatic aberration correction of the electron microscope objective lens, for the charged beam transport etc., [1-5]. The electrostatic multipole elements can be of the various shapes.

In this paper an electrostatic multipole system mathematical model of $2 K$ elements electrodes with sign-changing potentials at neighboring electrodes is described. It can be determined planes of antisymmetry $\alpha=k \pi / K, k=\overline{0, K-1}$ in polar coordinates $(r, \alpha)$. The radius of the systems area is $r=R_{0}$. Thus the sector $0 \leqslant \alpha \leqslant \pi / K, 0 \leqslant r \leqslant R_{0}$ is sufficient to solve the problem.

To calculate the potential distribution, each real electrode is changed by a virtual electrode whose surface coincides with an equipotential surface, so that the effect of the electrode on the electrostatic potential distribution is simulated as the effect of a $N$ charged lines $[6,7]$. Each charged line with the charge density $\tau_{i_{j} j}$ is located at $\left(R_{j}, \alpha_{i_{j}}\right)(j=\overline{1, M}$, $i_{j}=\overline{1, N_{j}}$ ). Figure 1 shows the schematic representation of the multipole system sector, where $\alpha_{0}=\pi / K$.

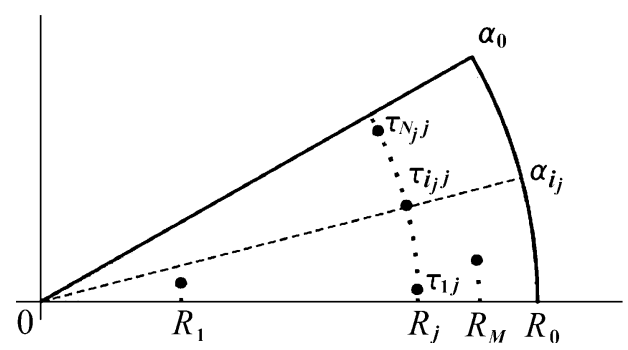

Fig. 1. Schematic representation of the multipole system sector

The problem parameters are: $R_{0}$ - the radius of the sector; $\alpha=0$ and $\alpha=\pi / K$ - the planes of antisymmetry and the sector boundaries with respect to a variable $\alpha ;\left(R_{j}, \alpha_{i_{j}}\right)-$ the coordinate position of the charged line $\left(j=\overline{1, M}, i_{j}=\overline{1, N_{j}}\right) ; \tau_{i_{j} j}$ - the line charge density; $N=M \sum_{j=1}^{M} N_{j}$ - the number of the charged lines.

Mathematical model. The electrostatic potential distribution $U(r, \alpha)$ in the area $\left(0 \leqslant r \leqslant R_{1}, 0 \leqslant \alpha_{0}=\pi / K\right)$ satisfies the Laplace equation and the boundary conditions

$$
\begin{gathered}
\frac{1}{r} \frac{\partial}{\partial r}\left(r \frac{\partial U}{\partial r}\right)+\frac{1}{r^{2}} \frac{\partial^{2} U}{\partial \alpha^{2}}=-\frac{\rho(r, \alpha)}{\varepsilon_{0}}, \\
U(r, 0)=0, \quad 0 \leqslant r \leqslant R_{0}, \\
U\left(r, \alpha_{0}\right)=0, \quad 0 \leqslant r \leqslant R_{0}, \\
U\left(R_{0}, \alpha\right)=0, \quad 0 \leqslant \alpha \leqslant \alpha_{0} .
\end{gathered}
$$

Each charged line with the coordinate position $\left(R_{j}, \alpha_{i_{j}}\right)$ and linear charge density $\tau_{i_{j} j}$ generates the space charge distribution $\rho_{i_{j} j}(r, \alpha)$ in the small volume $\left|r-R_{j}\right|<\delta$, $\left|\alpha-\alpha_{i_{j}}\right|<\varepsilon$ so that

$$
\rho(r, \alpha)= \begin{cases}\rho_{i_{j} j}=\mathrm{const}, & \left|r-R_{j}\right|<\delta \text { and }\left|\alpha-\alpha_{i_{j}}\right|<\varepsilon, \\ 0, & \left|r-R_{j}\right|>\delta \quad \text { or }\left|\alpha-\alpha_{i_{j}}\right|>\varepsilon,\end{cases}
$$


and

$$
\tau_{i_{j} j}=\lim _{\delta \rightarrow 0, \varepsilon \rightarrow 0} 4 \rho R_{j} \delta \varepsilon .
$$

The solution of the boundary - value problem. The variable separation method in polar coordinates is used to solve the boundary-value problem (1)-(4) [7-11].

The potential distribution $U(r, \alpha)$ as the solution of Poisson equation (1) with the homogeneous boundary conditions (2) with respect to a variable $\alpha$ can be presented as the expansion:

$$
U(r, \alpha)=\sum_{i=1}^{N} v_{n}(r) \sin \left(\frac{n \pi \alpha}{\alpha_{0}}\right) .
$$

The orthogonality conditions of the eigenfunctions $\sin \left(\frac{n \pi \alpha}{\alpha_{0}}\right)$

$$
\int_{0}^{\alpha_{0}} \sin \left(\frac{n \pi \alpha}{\alpha_{0}}\right) \sin \left(\frac{m \pi \alpha}{\alpha_{0}}\right) d \alpha= \begin{cases}\alpha_{0} / 2, & n=m \\ 0, & n \neq m\end{cases}
$$

allow to express the unknown functions $v_{n}(r)$ in terms of the function $U(r, \alpha)$ :

$$
v_{n}(r)=\frac{2}{\alpha_{0}} \int_{0}^{\alpha_{0}} U(r, \alpha) \sin \left(\frac{n \pi \alpha}{\alpha_{0}}\right) d \alpha .
$$

Then the Poisson's equation (1) can be multiplied by $\sin \left(n \pi \alpha / \alpha_{0}\right)$ and integrated from 0 to $\alpha_{0}$ and after some transformations the following equation can be obtained:

$$
\begin{gathered}
\int_{0}^{\alpha_{0}} \frac{\partial^{2} U(r, \alpha)}{\partial r^{2}} d \alpha+\frac{1}{r} \int_{0}^{\alpha_{0}} \frac{\partial U(r, \alpha)}{\partial r} \sin \left(\frac{n \pi \alpha}{\alpha_{0}}\right) d \alpha- \\
-\frac{1}{r^{2}}\left(\frac{n \pi}{\alpha_{0}}\right)^{2} \int_{0}^{\alpha_{0}} U(r, \alpha) \sin \left(\frac{n \pi \alpha}{\alpha_{0}}\right) d \alpha=-\frac{1}{\varepsilon_{0}} \int_{0}^{\alpha_{0}} \rho(r, \alpha) \sin \left(\frac{n \pi \alpha}{\alpha_{0}}\right) d \alpha .
\end{gathered}
$$

Making use of (7) the equation (8) can be written as

$$
\begin{aligned}
& v_{n}^{\prime \prime}(r)+\frac{1}{r} v_{n}^{\prime}(r)-\frac{1}{r^{2}}\left(\frac{n \pi}{\alpha_{0}}\right)^{2} v_{n}(r)=\phi(r), \\
& \phi(r)=-\frac{2}{\varepsilon_{0} \alpha_{0}} \int_{0}^{\alpha_{0}} \rho(r, \alpha) \sin \left(\frac{n \pi \alpha}{\alpha_{0}}\right) d \alpha .
\end{aligned}
$$

Formulae (2), (5), (6) lead to the boundary conditions for the functions $v_{n}(r)$ :

$$
v_{n}(0)=0, \quad v_{n}\left(R_{0}\right)=0 .
$$

The method of variation of constants is used to solve the second-order differential equation (9) and the solution can be written as

$$
v_{n}(r)=C_{1, n} r^{n \pi / \alpha_{0}}+C_{2, n} r^{-n \pi / \alpha_{0}}+
$$




$$
+\frac{\alpha_{0}}{2 n \pi} \int_{0}^{r} \eta\left[\left(\frac{r}{\eta}\right)^{n \pi / \alpha_{0}}-\left(\frac{\eta}{r}\right)^{n \pi / \alpha_{0}}\right] \phi(\eta) d \eta .
$$

The integration constants $C_{1, n}, C_{2, n}$ (11) are determined using the conditions (10):

$$
\begin{aligned}
C_{1, n} & =\frac{\alpha_{0}}{2 n \pi} R_{0}^{-n \pi / \alpha_{0}} \int_{0}^{R_{0}} \eta\left[\left(\frac{R_{0}}{\eta}\right)^{n \pi / \alpha_{0}}-\left(\frac{\eta}{R_{0}}\right)^{n \pi / \alpha_{0}}\right] \phi(\eta) d \eta, \\
C_{2, n} & =0 .
\end{aligned}
$$

Using the function $\rho_{i_{j} j}$ (3) in the right-hand side of the Poisson equation (1), the integration constants $C_{1, n}(12)$ can be calculated as

$$
\begin{aligned}
C_{1, n}=- & \frac{1}{n \pi \varepsilon_{0}} R_{0}^{-n \pi / \alpha_{0}} \sum_{j=1}^{M} \sum_{i_{j}=1}^{N_{j}} 4 \rho_{i_{j} j} \varepsilon \delta \sin \left(\frac{n \pi \alpha_{i_{j}}}{\alpha_{0}}\right) \times \\
\times & {\left[\left(\frac{R_{0}}{R_{j}}\right)^{n \pi / \alpha_{0}}-\left(\frac{R_{j}}{R_{0}}\right)^{n \pi / \alpha_{0}}\right] . }
\end{aligned}
$$

Then, making use of (4), (11), (13), the solution of ordinary differential equation (9) is

$$
\begin{gathered}
v_{n}(r)=-\frac{1}{n \pi \varepsilon_{0}}\left\{\sum_{j=1}^{k} \sum_{i_{j}=1}^{N_{j}} \tau_{i_{j} j} \sin \left(\frac{n \pi \alpha_{i_{j}}}{\alpha_{0}}\right)\left(\frac{R_{j}}{R_{0}}\right)^{n \pi / \alpha_{0}} \times\right. \\
\times\left[\left(\frac{R_{0}}{r}\right)^{n \pi / \alpha_{0}}-\left(\frac{r}{R_{0}}\right)^{n \pi / \alpha_{0}}\right]+ \\
\left.+\sum_{j=k+1}^{M} \sum_{i_{j}=1}^{N_{j}} \tau_{i_{j} j} \sin \left(\frac{n \pi \alpha_{i_{j}}}{\alpha_{0}}\right)\left[\left(\frac{R_{0}}{R_{j}}\right)^{n \pi / \alpha_{0}}-\left(\frac{R_{j}}{R_{0}}\right)^{n \pi / \alpha_{0}}\right]\left(\frac{r}{R_{0}}\right)^{n \pi / \alpha_{0}}\right\}, \\
R_{k} \leqslant r \leqslant R_{k+1} .
\end{gathered}
$$

Thus, the potential distribution $U(r, \alpha)(5),(14)$ is calculated in analytic form.

Numerical results. The values of the parameters are taken in relation to respective maximum values to calculate the potential distribution.

The following parameters are used: $M=1, R_{1}=0.5, R_{0}=1.0, \alpha_{0}=\pi / 4, \varepsilon_{0}=1.0$.

Figure 2 presents the equipotential lines of the potential distribution in the entire area of the multipole system sector for $N=1, \alpha_{1}=\pi / 8, \tau_{1}=9785$.

Figure 3 shows the equipotential lines of the potential distribution in the entire area of the multipole system sector for $N=4, \alpha_{k}=k \pi / 16(k=\overline{1,4}), \tau_{1}=4, \tau_{2}=63, \tau_{3}=59$, $\tau_{4}=92$.

Figure 4 presents the equipotential lines of the potential distribution in the entire area of the multipole system sector for $N=8, \alpha_{k}=k \pi / 44(k=\overline{1,8}), \tau_{1}=16, \tau_{2}=27$, $\tau_{3}=23, \tau_{4}=30, \tau_{5}=33, \tau_{6}=41, \tau_{7}=50, \tau_{8}=67$.

Figure 5 presents the equipotential lines of the potential distribution in the entire area of the multipole system sector for $N=18, \alpha_{k}=k \pi / 76(k=\overline{1,18}), \tau_{1}=10, \tau_{2}=6$, $\tau_{3}=12, \tau_{4}=8, \tau_{5}=11, \tau_{6}=12, \tau_{7}=11, \tau_{8}=14, \tau_{9}=14, \tau_{10}=15, \tau_{11}=18, \tau_{12}=18$, $\tau_{13}=21, \tau_{14}=25, \tau_{15}=27, \tau_{16}=35, \tau_{17}=42, \tau_{18}=55$. 


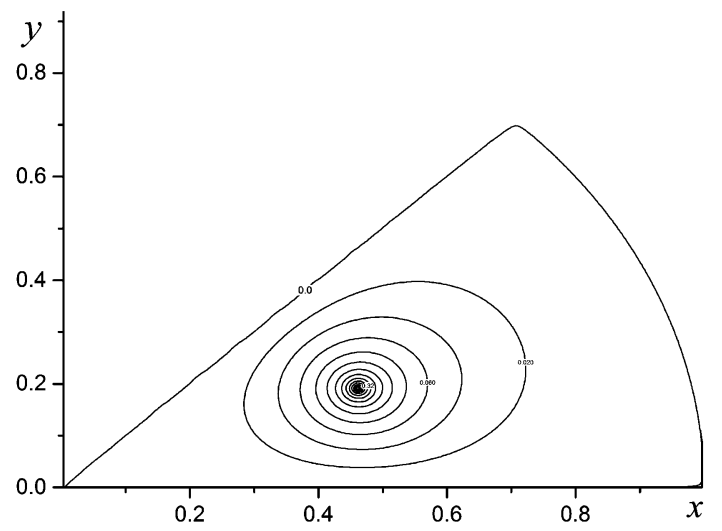

Fig. 2. The equipotential lines of the potential distribution for $N=1$

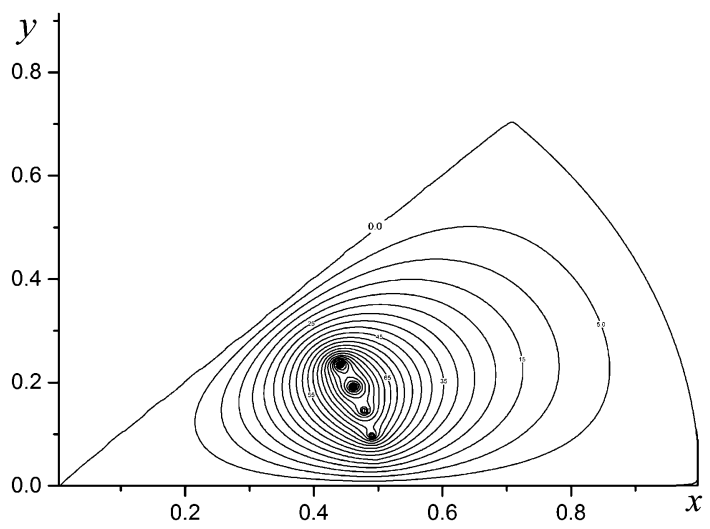

Fig. 3. The equipotential lines of the potential distribution for $N=4$

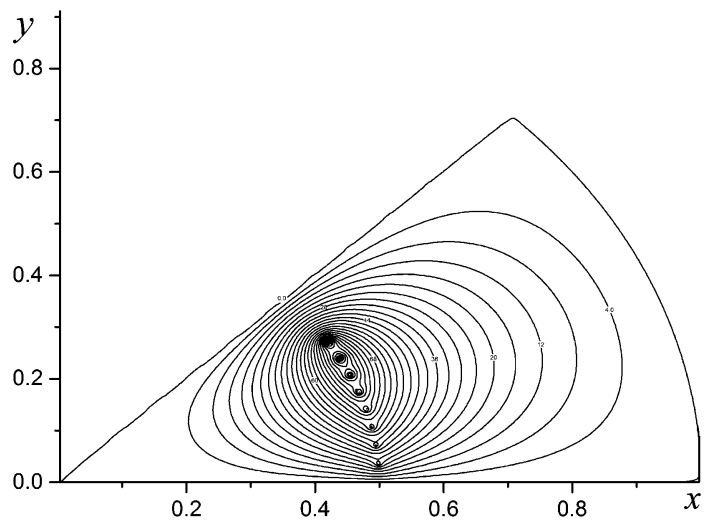

Fig. 4. The equipotential lines of the potential distribution for $N=8$ 


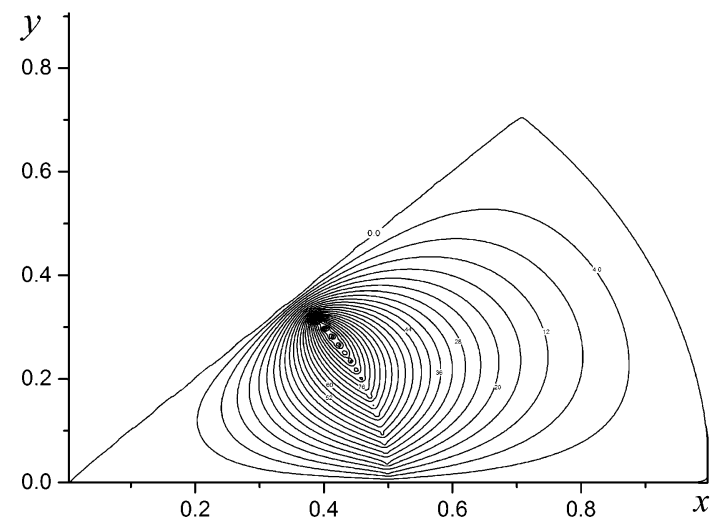

Fig. 5. The equipotential lines of the potential distribution for $N=18$

Conclusion. In this article a multipole system mathematical modeling is presented. The multipole system consists of even number equiform electrostatic electrodes. The constant potential is equal in absolute value and sign-changing at neighboring elements. The effect of the electrode on the electrostatic potential distribution is simulated as the effect of the charged lines. Thus, each real electrode is changed by a virtual electrode whose surface coincides with an equipotential surface to find the potential distribution. The variable separation method is used to solve the boundary-value problem for Poisson equation in plane polar coordinates. The electrostatic potential distribution function is calculated as series (5), (14) in an analytic form. In this way the distribution of the potentials for the whole region of the considered multipole systems is obtained. In accordance with the analytical resulting formulae the equipotential lines for a different number of charged lines are represented by the diagrams. Any of the equipotentials can be regarded as the electrode surface. Numerical calculations show the multipole system mathematical model adequacy. The presented technique and formulae for the electrostatic potential distribution can be used for the electrodes with a complex-shaped surface modeling.

\section{References}

1. Hawkes P. W. The correction of electron len saberrations. Ultramicroscopy, 2015, vol. 156, pp. A1-A64.

2. Baranova L. A., Read F. H., Cubric D. Computational simulation of an electrostatic aberration corrector for a low-voltage scanning electron microscope. Nuclear Instruments and Methods in Physics Research A, 2004, vol. 519, pp. 42-48.

3. Baranova L. A., Read F. H. Minimisation of the aberrations of electrostatic lens systems composed of quadrupole and octupole lenses. International Journal of Mass Spectrometry, 1999, vol. 189, pp. 19-26.

4. Munro E., Rouse J., Liu H., Wang L. Aberration correction for electron beam inspection, metrology and lithography. Journal of Vacuum Science and Technology B: Microelectronics and Nanometer Structures, 2008, vol. 26, no. 6, pp. 2331-2336.

5. Zach J., Haider M. Aberration correction in a low voltage SEM by a multipole corrector. Nuclear Instruments and Methods in Physics Research A, 1995, vol. 363, pp. 316-325.

6. Vinogradova E. M., Egorov E. N., Televnyy D. S. Mathematical modeling of field emitter array. Vacuum, 2016, vol. 127, pp. 45-50.

7. Vinogradova E. M., Egorov E. N., Klimakov A. A. Mathematical simulation of a diode system with a cylindrical field-emission tip. Technical Physics, 2015, vol. 60, no. 2, pp. 176-179.

8. Starikova A. V., Vinogradova E. M. The electrostatic octupole lens mathematical modeling. 2016 Young Researchers in Vacuum Micro/Nano Electronics, VMNE-YR 2016 - Proceedings, 16 March, 2017, Article no. 7880416.

9. Vinogradova E. M., Lisrtukova A. V. Matematicheskoe modelirovanie kvadrupol'noj jelektro- 
staticheskoj linzy [The electrostatic quadrupole lens mathematical modeling]. Vestnik of Saint Petersburg State University. Series 10. Applied Mathematics. Computer Science. Control Processes, 2016, iss. 1, pp. 19-27. (In Russian)

10. Vinogradova E. M., Egorov N. V., Starikova A. V., Varayun M. I. Calculating a Multipole Cylindrical Electrostatic System. Technical Physics, 2017, vol. 62, no. 5, pp. 791-794.

11. Vinogradova E. M., Starikova A. B. The multipole lens mathematical modeling. Proceedings of RuPAC 2016. Saint Petersburg, Russia, Saint Petersburg State University Publ., 2016, pp. 535-537.

For citation: Vinogradova E. M., Starikova A. V., Varayun' M. I. Multipole electrostatic system mathematical modeling. Vestnik of Saint Petersburg University. Applied Mathematics. Computer Science. Control Processes, 2017, vol. 13, iss. 4, pp. 365-371. https://doi.org/10.21638/11701/spbu10.2017.403

Статья рекомендована к печати проф. Н. В. Егоровым.

Статья поступила в редакцию 11 октября 2017 г.

Статья принята к печати 12 октября 2017 г. 